\title{
Sosialisasi Pengenalan Potensi Laut Alga Cokelat Sargassum sp Sebagai Pengawet Alami Mie Aceh Kepada Masyarakat
}

\author{
Mohamad Gazali1 ${ }^{\text {, Rina Syafitri }}{ }^{2}$, Zuriat ${ }^{3}$, Arfriani Maifizar ${ }^{4}$, Muzakkir ${ }^{5}$ \\ 1Jurusan Ilmu Kelautan , Fakultas Perikanan dan Ilmu Kelautan Universitas Teuku Umar \\ Email: mohamadgazali@utu.ac.id \\ 2Jurusan Agribisnis, Fakultas Pertanian Universitas Teuku Umar \\ Email: rinasyafitri@utu.ac.id \\ 3Jurusan Perikanan, Fakultas Perikanan dan Ilmu Kelautan Universitas Teuku Umar \\ Email: mohamadgazali@utu.ac.id \\ 4Jurusan Sosiologi, Fakultas Ilmu Sosial dan Politik, Universitas Teuku Umar \\ Email:_arfrianimaifizar@utu.ac.id \\ 5Jurusan Ilmu Komunikasi, Fakultas Ilmu Sosial dan Politik, Universitas Teuku Umar \\ Email: muzakkir@utu.ac.id
}

\begin{abstract}
The west Aceh coast have the high potency of marine resources for fulfilling human needs. One of potency of marine resources is marine algae Sargassum sp. Sargassum sp is one of the seaweed that possesses highly antioxidant and antibacterial content. Therefore, the researcher conducted service community programme including the engagement of PkM partner and socialization of marine algae laut Sargassum $s p$ as natural preservation. Part of Aceh noodle producer produce the Aceh noodle in big scale in turn out the Aceh Noodle were not sold. It is caused Aceh Noodle producer use chemical formalin as Aceh Noodle preservation. Nevetheless, formalin is dangerous chemical for our health if It consumed by human. The aim of this community service programme are to give understanding to PkM partner and community regarding marine alga Sargassum of utilization of marine algae Sargassum sp as natural preservation. Conducting method includimg the engagement of PkM Partner and the socialization of marine alga Sargasssum $\mathrm{sp}$ introduction as natural preservation of Aceh Noodle. The stage of community service phase of community service including survey, preparation of chemist and tools for sozialization of marine alga Sargassum sp as natual preservation of Aceh Noodle and engagement of partner PkM as transfer knowledge, in the community service including the engagement of pkm partner and the socialization of community. Firstly, the researcher undertaken the partner engagement and community socialization with addition of brown algae Sargassum sp extract as natural preservation. Secondly, the researcher conducted the socialization of marine algae Sargassum sp to community.
\end{abstract}

Keywords ; socialization, natural preservation, Sargassum sp

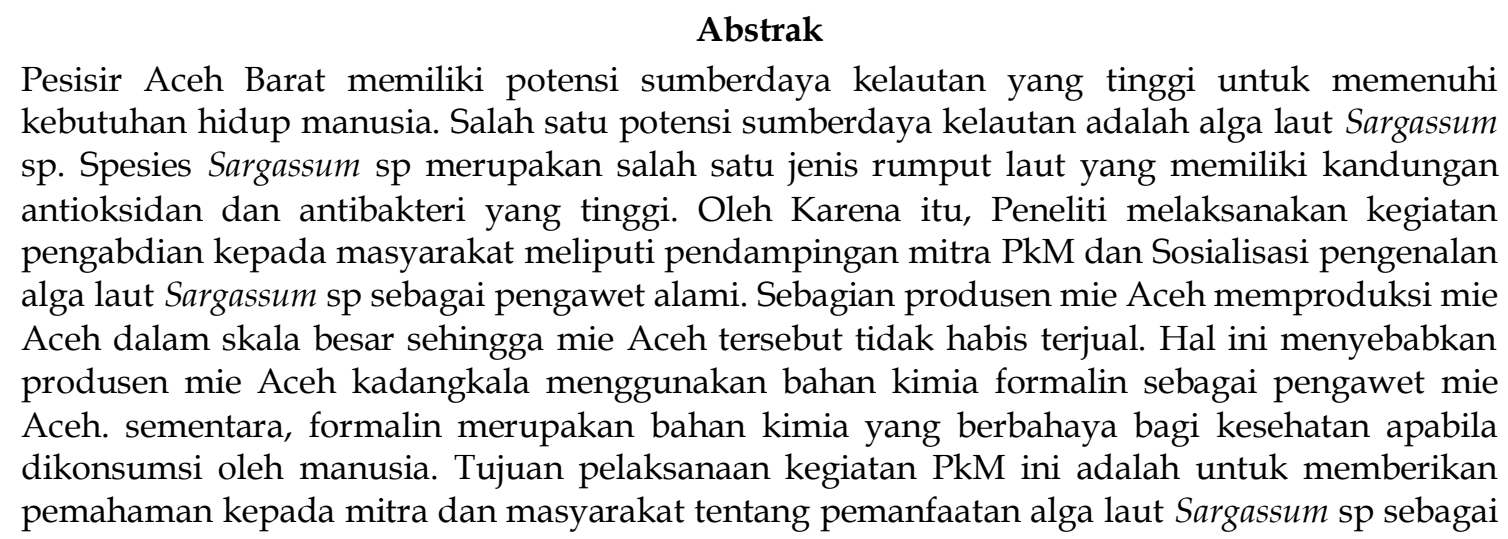


pengawet alami. Metode pelaksanaan kegiatan PkM meliputi pendampingan mitra PkM dan sosialisasi pengenalan potensi alga laut Sargassum sp sebagai pengawet alami Mie Aceh and knowledge transfer. Tahapan pelaksanaan kegiatan pengabdian kepada masyarakat meliputi survey ketersediaan bahan baku alga cokelat di perairan Aceh Barat, persiapan alat dan bahan untuk kegiatan sosialisasi kepada masyarakat dan pendampingan mitra PkM sebagai bentuk transfer knowledge. Dalam pelaksanaan kegiatan PkM ini meliputi pendampingan mitra PkM dan sosialisasi kepada masyarakat. Pertama, peneliti melakukan pendampingan mitra dalam pembuatan mie Aceh dengan menambahkan ekstrak alga cokelat Sargassum sp sebagai pengawet alami. Kedua, peneliti melaksanakan sosialisasi potensi alga laut Sargassum sp kepada masyarakat.

Kata Kunci: Sosialisasi, Pengawet alami, Sargassum sp

\section{PENDAHULUAN}

Perairan laut Indonesia merupakan wilayah laut tropis dengan sumberdaya plasma nutfah makroalga laut yang terindentifikasi \pm 782 spesies dalam ekspedisi laut sibolga pada tahun 1899-1990 oleh Van Bosse). Genus makroalga laut yang sering dijumpai di perairan laut Indonesia adalah Gracilaria, Gelidium, Eucheuma, Hypnea, Sargassum, dan Turbinaria yang dikembangkan menjadi marine natural product yang dimanfaatkan untuk kepentingan industri farmasi dan kosmetik (Kementerian Kelautan dan Perikanan RI, 2008).

Makroalga laut atau lebih dikenal dengan rumput laut sudah banyak dimanfaatkan oleh masyarakat lokal dan beberapa spesies makrolaga laut sudah dibudidayakan dengan berbagai model budidaya laut (marikultur) sehingga perairan tropis Indonesia merupakan habitat yang layak bagi pertumbuhan makroalga laut dengan keanekaragaman hayati laut yang sangat pesat yang berada pada segitiga terumbu karang.

Perairan Barat selatan Aceh mempunyai karakteristik pesisir dan laut yang cocok dengan pertumbuhan alga laut yang meliputi alga hijau, alga cokelat dan alga merah.

Alga laut adalah salah satu komoditas perikanan yang memiliki nilai ekonomis penting sebagai bahan makanan dan kepentingan industry (Critchley et al., 2006). Alga laut diduga memiliki kandungan senyawa polisakarida yang meliputi alginat, agar-agar dan karaginan. Selain itu, makroalga laut juga memiliki kandungan pigmen yang memberikan warna khas makroalga laut (Dewangga, 2008; Kusumastuti, 2008; Merdekawati, 2009; Resita, 2008). Menurut Lila (2004) bahwa makroalga laut memiliki tiga jenis pigmen utama yaitu klorofil, karotenoid, dan fikosianin.

Gazali dan Nurdin (2017) melaporkan bahwa Pesisir Aceh Barat memiliki biodiversitas 
makroalga laut yang tinggi yang terdiri dari 11 spesies alga cokelat seperti Dictyota dichotoma, D. ciliolata, Dictyopteris delicatula, Turbinaria ornata, Padina australis, $P$. Minor, Sargasssum ilicifolium, $S$. polycystum, S. duplicatum, S. vulgare dan Cystoseira compressa. Alga hijau meliputi Chaetomorpha crassa, Cladophora sp, Codium fragile, Enteromorpha flexuosa, Chlorodesmis fastigiata, Boegeisenia forbesii, Caulerpa racemosa, C. sertulariodes, Halimeda micronesia dan $H$. macroloba. Sementara Alga merah terdiri dari 6 spesies meliputi Haliptilon virgatum, Laurencia obtusa, L. complanata, Gastroclonium subarticulatum, Neogastroclonum subarticulatum dan Thamnoclonium dichotomum.

Makroalga laut yang sudah dilakukan ekstraksi untuk diidentifikasi senyawa bioaktif seperti makroalga laut Chaetomorpha antennina (Gazali dan Nasution, 2019), spesies Sargassum sp, dan beberapa spesies makroalga laut yang disudah dilakukan penguijan laboratorium.

Beberapa spesies yang ada di Pesisir Lhok Bubon spesies yang paling mendominasi adalah alga cokelat (Sargassum sp.). Spesies alga cokelat ini lebih berlimpah dibandingkan dengan spesies alga lainnya yang selalu ada setiap tahun.
Pemanfaatan potensi alga laut cokelat (Sargassum sp) sebagai pengawet alami pada mie Aceh memiliki prospek cerah yang memberikan nilai tambah (value added) bagi masyarakat pesisir. Masyarakat Vietnam bagian selatan hingga tengah seperti Khanh Hoa, Quang Nam, Quang Ngai, Binh Dinh, telah memanfaatkan Sargassum dan Porphyra sebagai minuman teh yang berkhasiat medis. Pemanfaatan teh Sargassum oleh masyarakat Vietnam ini telah dilakukan sejak lama (Susanto, 2009).

Hal ini dipertimbangan adanya bahan baku alga cokelat Sargassum sp dapat dimanfaatkan secara berkelanjutan (sustainablity). Kegiatan PkM ini berkaitan dengan hasil riset yang sudah dilakukan oleh Gazali et al., (2018) bahwa alga laut Sargassum sp mempunyai potensi sebagai antioksidan dengan nilai $\mathrm{IC}_{50}$ sebesar $39,51 \mathrm{mg} / \mathrm{L}$, etil asetat ekstrak 68,89 mg/L dan nheksan ekstrak $148.16 \mathrm{mg} / \mathrm{L}$. Ekstrak Sargassum sp Agardh terdeteksi mengandung fenol, alkaloid dan triterpenoid. Selain itu, Gazali et al., (2018) melaporkan zona hambat ekstrak Sargassum sp pada E.coli adalah 8,11 mm, 6,92 $\mathrm{mm}$ dan 6,65 mm pada konsentrasi yang berbeda. Gazali (2018) juga melaporkan bahwa alga laut Sargassum sp Agardh memiliki 
aktivitas inhibitor tirosinase dengan nilai $\mathrm{IC}_{50}$ sebesar $1111.49 \mu \mathrm{g} / \mathrm{ml}$ jalur monofenolase dan $\mathrm{IC}_{50}=$ $1582.31 \mu \mathrm{g} / \mathrm{ml}$ jalur difenolase.

Selain itu, ada beberapa kasus yang terjadi bahwasanya ada beberapa produsen mie Aceh yang masih menggunakan pengawet formalin karena mereka memproduksi skala massal sehingga kadangkala mie Aceh tidak terjual habis. Formalin yang digunakan untuk mengawetkan mie Aceh merupakan pangawet kimiawi yang berbahaya bagi kesehatan tubuh apabila dikonsumsi secara berlebihan.

Hal ini menjadi iniasitif bagi kami untuk melakukan program pengabdian kepada masyarakat dengan memperkenalkan potensi laut alga cokelat Sargassum sp sebagai pengawet alami mie Aceh kepada masyarakat Aceh Barat. Tujuan kegiatan pengabdian kepada masyarakat ini adalah untuk memberikan informasi dan pengetahuan baru kepada masyarakat awam terkait potensi laut alga cokelat Sargassum $\mathrm{sp}$ sebagai pengawet alami pada mie Aceh.

\section{METODE PELAKSANAAN}

\section{Khalayak Sasaran}

Profil masyarakat sasaran yaitu masyarakat lokal yang meliputi produsen mie aceh, penjual mie aceh dan konsumen mie aceh. Mitra PkM adalah Usahawan Pengolah Mie Aceh yang berdomisili di Kota Meulaboh.

\section{Metode Kegiatan}

Metode pelaksanaan kegiatan pengabdian kepada masyarakat berupa pendampingan mitra dan sosialisasi pengenalan potensi alga cokelat (Sargassum sp) sebagai pengawet alami. Kegiatan pengabdian kepada masyarakat dilaksanakan pada tanggal 18 Septermber 2020 di Mie Ampon Teeh Desa Alue Peunyareng.

Tahapan pelaksanaan kegiatan pengabdian kepada masyarakat meliputi survey ketersediaan bahan baku alga cokelat di perairan Aceh Barat. Tahapan pelaksanaan Program Pengabdian kepada masyarakat. Pertama, survey dan pengumpulan bahan baku alga laut cokelat Sargassum sp dilakukan di sepanjang zona intertidal (Intertidal zone) Lhok Bubon Kecamatan Samatiga Kabupaten Aceh Barat Propinsi Aceh. Pengambilan bahan baku dilakukan dengan tetap menjaga keberlanjutan ekosistem laut dengan tidak merusak habitat dan menyisahkan bagian thalus makroalga laut agar dapat lestari.

Kedua, persiapan peralatan untuk melakukan produksi mie Aceh Sargassum. Peralatan yang digunakan untuk produksi mie 
Aceh Sargassum sudah tersedia di lokasi mitra PKM sehingga memudahkan peneliti melaksanakan kegiatan pengabdian kepada masyarakat.

Ketiga, kegiatan pelatihan pembuatan mie Aceh Sargassum sebagai pengawet alami dengan melibatkan mitra PkM yakni UD Aneka Mie dimana Usaha tersebut sudah berjalan dalam jangka waktu yang lama dan memperoleh omzet produksi mie Aceh sekitar Rp. 1.500.000 per hari.

\section{Keempat, kegiatan} penyuluhan kepada masyarakat dengan memberikan berbagai informasi akan bahaya penggunaan formalin dan boraks dalam pembuatan mie Aceh yang berdampak pada kesehatan masyarakat. Selain itu, peneliti memberikan alternatif dengan melakukan konversi pengawet kimia pada pengawet alami yang berasal dari makroalga laut Sargassum sp. Kegiatan penyuluhan kepada masyarakat dan pendampingan mitra $\mathrm{PkM}$ sebagai bentuk transfer knowledge.

Kelima, kegiatan pendampingan mitra $\mathrm{PkM}$ dengan melakukan kolaborasi untuk menghasilkan produk mie Aceh yang aman dan bernilai tambah dalam bidang kesehatan.
3. HASIL DAN PEMBAHASAN

\section{A. Pengambilan Bahan Baku}

Untuk menyediakan bahan baku, kami melakukan pengambilan bahan baku (raw material) di wilayah Pesisir Lhok Bubon Aceh Barat. Dalam pengambilan bahan baku, kami melibatkan 2 orang mahasiswa Prodi Ilmu Kelautan dalam melakukan pengambilan bahan baku makroalga laut di pesisir pantai. Setelah alga cokelat Sargassum sp didapatkan kemudian dibersihkan dengan air tawar dikeringkan anginkan selama beberapa hari. Hal ini bertujuan agar senyawa aktif yang terdapat pada makroalga tidak rusak akibat radiasi UV sinar matahari. Setelah dikeringkan, kemudian alga cokelat Sargassum sp tersebut kami bawa ke pasar untuk digiling sehingga memperoleh simplisia yang siap digunakan sebagai pengawet alami

\section{B. Pelatihan Pembuatan Mie Aceh dengan Pengawet Alami}

Pengabdian kepada masyarakat dengan melakukan pelatihan kepada mitra PkM. Peneliti mencoba bersama mitra PkM mencoba melakukan inovasi baru dengan memanfaatkan alga cokelat sebagai pengawet alami.

Peneliti melakukan uji coba pada Mie Aceh yang biasa dengan 
mie Aceh dengan menambahkan ekstrak Sargassum sp sebagai pengawet alami tanpa efek samping. Hasil uji coba bahwa mie Aceh dengan penambahan ekstrak alga laut Sargassum sp ternyata memberikan daya tahan mie Aceh selama $10 \mathrm{jam}$. Dalam proses uji coba dengan mie Aceh sebagai kontrol positif. Hal ini membuktikan bahwa Mie dengan mengunakan Sargassum sp sebagai pengawet memiliki kemampuan menghambat mikroorganisme.
Pengabdian masyarakat dengan melakukan pendampingan. Peneliti mencoba bersama mitra PkM mencoba melakukan inovasi baru dengan memanfaatkan alga cokelat sebagai pengawet alami.

Dalam pendampingan mitra PkM melibatkan mahasiswa Jurusan Ilmu Kelautan Fakultas Perikanan dan Ilmu Kelautan Universitas Teuku Umar sebagai proses pembelajaran.

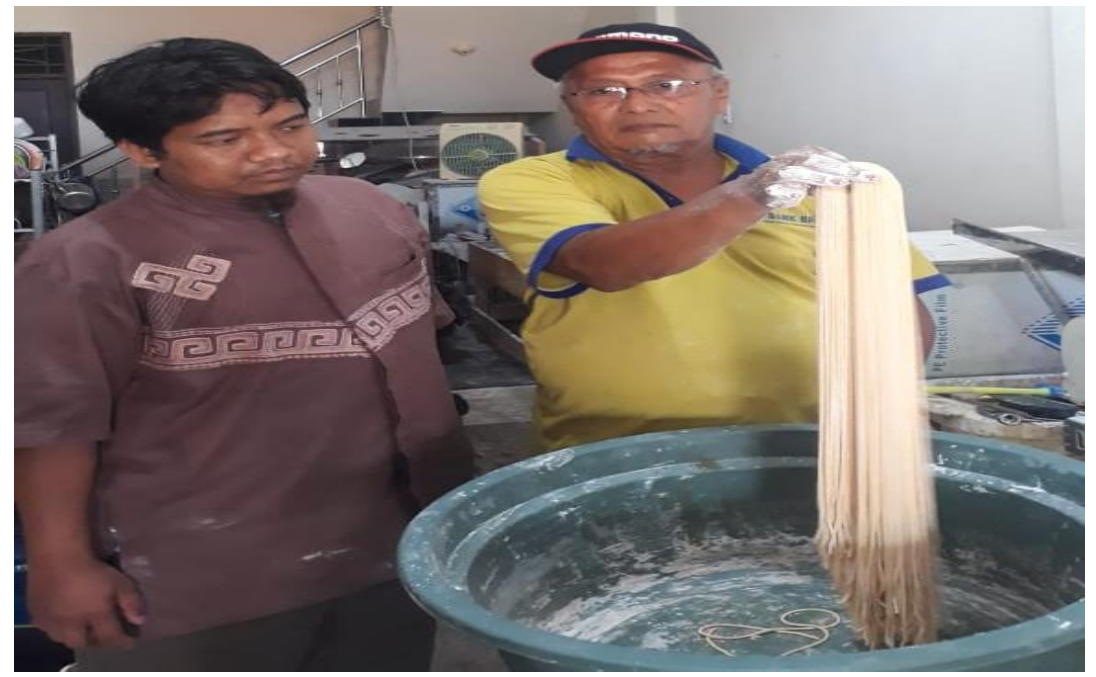

Gambar 1. Pelatihan Pembuatan Mie Aceh Sargassum dengan mitra PkM

\section{Penyuluhan Kepada Khalayak Masyarakat \\ Peneliti melaksanakan} sosialisasi kepada masyarakat Aceh Barat yang bekerjasama dengan mitra PkM yang memperkenalkan fungsi Sargassum sp yang berasal dari Perairan Aceh Barat memiliki kemampuan dalam menghambat mikroorganisme. Selain itu, alga laut Sargassum sp memiliki senyawa bioaktif yang menangkal radikal bebas yang menyebabkan berbagai macam penyakit seperti kanker, peradangan, penuaan dan penyakit lainnya.

Dalam sosialisasi pengenalan potensi alga laut Sargassum $\mathrm{sp}$ sebagai pengawet alami diikuti oleh 
khalayak sasaran PkM meliputi masyarakat, pedagang mie dan produsen mie Aceh serta konsumen mie Aceh. Gambar 2. Penyuluhan Pengenalan Sargassum sp kepada masyarakat

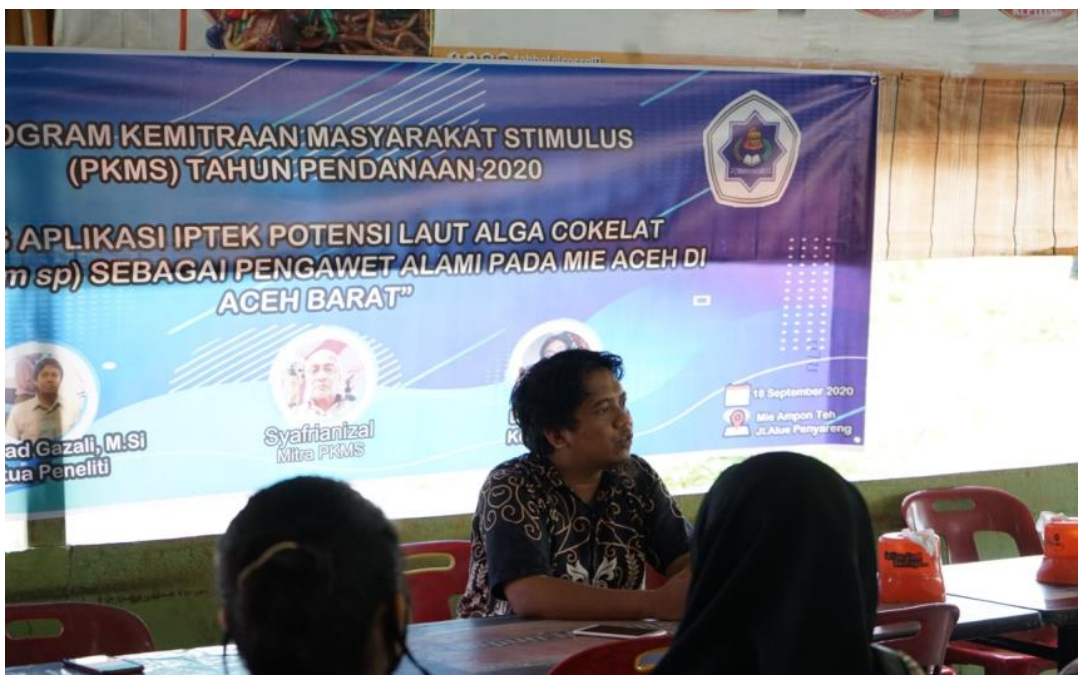

Gambar 2. Penyuluhan kepada Khayalak Masyarakat

Kegiatan pengabdian tersebut masyarakat sangat antusias mengikuti kegiatan tersebut. Outcome dari kegiatan PkM ini adalah pemahaman masyarakat terhadap manfaat alga laut Sargassum sp bagi kesehatan tubuh. Alga laut Sargassum sp mudah didapatkan di perairan yang belum dimanfaatkan secara optimal oleh masyarakat lokal. Oleh karena itu, kami berupaya memperkenalkan potensi alga laut melalui sosialisasi PkM ini.

Sebelumnya, Gazali (2019) melaksanakan Sosialisasi Pengenalan Potensi Sumberdaya Kelautan Dengan Pendekatan Bioprospeksi Kelautan Kepada Masyarakat Pesisir Lhok Bubon
Aceh Barat. kami menjelaskan potensi laut yang ada di Aceh Barat dapat dimanfaatkan untuk meningkatkan taraf hidup masyarakat. Lebih lanjut, Gazali dan Zuriat (2019), melaksanakan sosialisasi kepada masyarakat pesisir Lhok Bubon tentang potensi pemanfaatan alga cokelat Sargassum sp sebagai teh yang memiliki kandungan antioksidan yang tinggi.

Pendampingan ini akan berlangsung selama tiga bulan dengan tiga tahap kegiatan. "Pertama adalah sosialisasi pelaksanaan, kedua pelatihan selama dua hari, kemudian tahapan ketiga adalah pembinaan pasca pelatihan. Kita ketahui bahwa Pesisir Aceh Barat memiliki potensi 
sumberdaya laut yang sangat besar untuk dikembangkan untuk memenuhi kebutuhan masyarakat Aceh. Salah satu potensi sumberdaya laut adalah makroalga laut atau yang lebih dikenal dengan istilah rumput laut.

\section{Produk Mie Aceh Sargassum} peneliti berhasil memperkenal

produk Mie Aceh dengan makroalga laut sebagai pengawet alami yang aman bagi kesehatan tubuh tanpa adanya zat-zat kimia yang bersifat karsinogen. Adapun produk-produk mie Aceh dengan pengawet alga cokelat dapat disajikan pada Gambar 3.

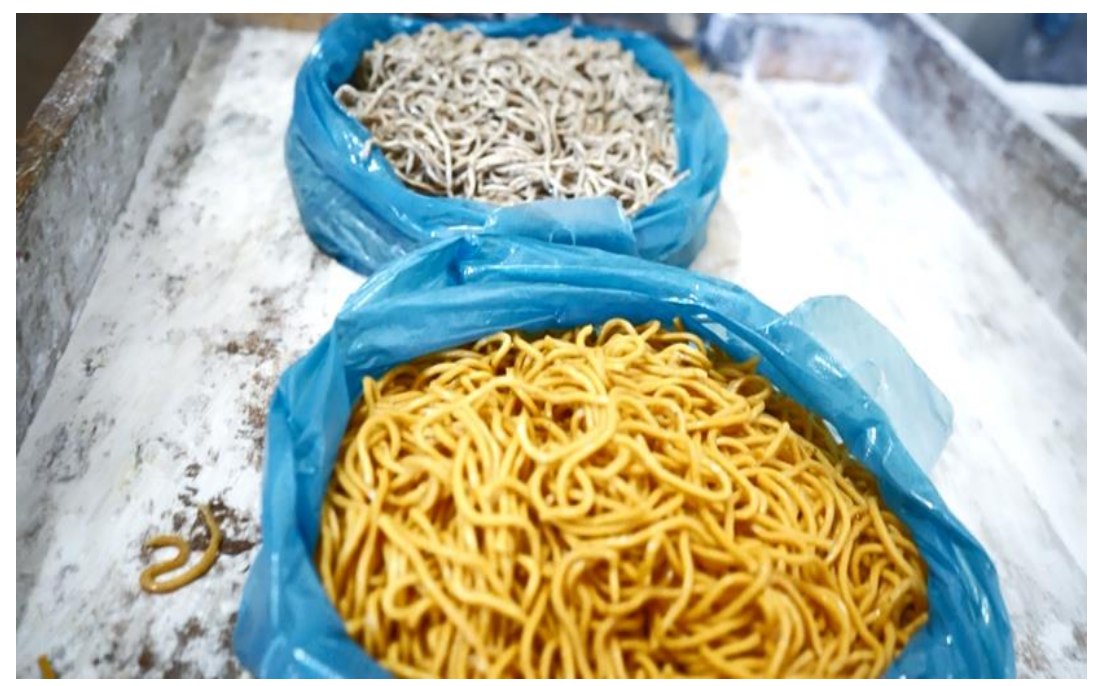

Gambar 3. Produk Mie Aceh dengan penambahan pengawet alami

\section{PENUTUP}

Program pengabdian ini dapat diselenggarakan dengan baik dan berjalan dengan lancar sesuai dengan rencana kegiatan yang telah disusun meskipun kebanyakan siswa belum terlalu familiar dengan materi yang berkaitan dengan.

Penulis mengucapkan terima kasih kepada Bapak Syafrinizal selaku mitra PkMS yang bersedia bekerjasama dalam melaksanakan kegiatan PkM. Ucapan terima kasih yang setingginya kepada DRPM Dikti yang memberikan pendanaan Program Kemitraan Masyarakat Stimulus (PKMS) dengan Nomor Kontrak : B/667/E.3.3/RA.03/2020.

\section{DAFTAR PUSTAKA}

Critchley A, Ohno M, Largo D. 2006. The Seaweed Resources of the World. Amsterdam (NL): ETI. 
Dewangga, I.G. 2008. Studi Pengaruh Pengeringan

Terhadap Kandungan dan Komposisi Pigmen Utama Rumput Laut Kappaphycus alvarezii (Doty) Doty (1986). Skripsi. Universitas

Diponegoro. Semarang.

Gazali M and Nurdin M. 2017. Biodiversity of Marine Macroalgae in The Intertidal Zone of Lhok Bubon Beach, West Aceh, Aceh Province. Proceeding The 4th International Marine and Fisheries Symposium 2017 Fakultas Ilmu Kelautan dan Perikanan Universitas Hasanuddin.

Gazali M, Nurjanah, Zamani NP. 2018. Eksplorasi senyawa bioaktif alga cokelat sargassum sp. Agardh sebagai antioksidan dari pesisir barat Aceh. Jurnal Pengolahan Hasil Perikanan Indonesia (JPHPI). Volume 21 Nomor 1. Hal 167-178.

Gazali M, Safutra E dan Zulfadhli. 2017. Eksplorasi Potensi Senyawa Bioaktif Makroalga Laut Sargassum sp Sebagai Antibakteri Asal Pesisir Barat Selatan (Barsela) Aceh. Prosiding SEMDI-UNAYA (Seminar Nasional Multi Disiplin Ilmu UNAYA) 1, 289300 | vol: | issue : | 2017.
Gazali M. 2018 Aktivitas Inhibitor Tirosinase pada Ekstrak Alga Cokelat Sargassum sp. Agardh Asal Pesisir Lhok Bubon, Kabupaten Aceh Barat. Jurnal Perikanan Terpadu Vol 1. Nomor 1. Hal 26-40.

Gazali M, Zuriat. 2019. Sosialisasi Potensi Lokal Aceh Barat Melalui Pemanfaatan Alga Cokelat (Sargassum sp) Kepada Masyarakat Pesisir Di Pantai Lhok Bubon Aceh Barat. Jurnal Marine Kreatif. Vol 3, No 2. Hal 14-20.

Gazali M dan Nasution MA. 2019.

Aktivitas Antioksidan Ekstrak Rumput Laut Chaetomorpha Antennina Asal Pesisir Ujong Serangga Aceh Barat Daya. Jurnal Laot Ilmu Kelautan. 1(1) : 20-29.

Gazali M. 2019. Sosialisasi Pengenalan Potensi Sumberdaya Kelautan Dengan Pendekatan Bioprospeksi

Kelautan Kepada Masyarakat Pesisir Lhok Bubon Aceh Barat. Jurnal Marine Kreatif. Vol 3, No 1. Hal 8-14.

Kusumastuti, K. 2008. Pengaruh Pengeringan Terhadap Komposisi dan Kandungan Pigmen Algae Hijau Caulerpa sp. Skripsi. Universitas Diponegoro. Semarang.

Lila, M.A. 2004. Plant pigments and human health. In: Davis, Plant 
Pigments and Their

Manipulation. CRC Press.

London. p. 248-274.

Merdekawati, W. 2009. Kandungan

dan aktivitas antioksidan

klorofil a dan b-karoten

Sargassum sp. Jurnal Kelautan

Nasional. 2: 144-145.

Resita, D. 2008. Kandungan dan

Komposisi Pigmen Sargassum

sp. pada Perairan Teluk Awur, Jepara dengan Perlakuan Segar dan Kering. Skripsi. Universitas Diponegoro. Semarang.

Susanto AB. 2009. Potensi Rumput Laut Sebagai Bahan Campuran MinumanTeh.

http://rumputlaut.org/tag/sar gassum/. Yayasan Rumput Laut Indonesia (YRLI). [24 Juni 2019]. 